\title{
Vulnerabilidade em saúde, educação e liberdade: reflexão à luz de Hannah Arendt
}

\author{
Vulnerability in health, education and freedom: reflection in the light of Hannah Arendt \\ Vulnerabilidad en salud, educación y libertad: reflexión a la luz de Hannah Arendt
}

\begin{abstract}
Virna Ribeiro Feitosa Cestari ${ }^{1}$ (1) Raquel Sampaio Florêncio ${ }^{1}$ (1) Vera Lúcia Mendes de Paula Pessoa ${ }^{1}$ Thereza Maria Magalhães Moreira ${ }^{1}$ (1)

1. Universidade Estadual do Ceará. Fortaleza, $\mathrm{CE}$, Brasil.
\end{abstract}

\begin{abstract}
REsUMO
Objetivo: refletir sobre o conceito de vulnerabilidade em saúde à luz dos pressupostos de educação e liberdade de Hannah Arendt. Método: estudo teórico-reflexivo cujos resultados foram agrupados em duas categorias:Vulnerabilidade em saúde como condição humana e Educação e liberdade do sujeito em situação de vulnerabilidade. Resultados: a vulnerabilidade deve ser reconhecida como traço da condição humana, pois suas dimensões envolvem o sujeito e suas condições de saúde, materiais, socioambientais, culturais e jurídicas. Ao considerar a vulnerabilidade na perspectiva política e conscientizadora, a educação emerge como ferramenta para sobrepujá-las, pois possibilita desenvolver as singularidades dos sujeitos, preparando-os para a responsabilidade com o mundo; propicia superar a alienação; concretiza o aprendizado político e a tomada de decisões Tudo isso reunido é crucial para suplantar a condição de vulnerabilidade frente às desigualdades existentes no mundo e o respeito à liberdade dos sujeitos. Conclusão e implicações para a prática: pensamentos arendtianos guardam relação com vulnerabilidade, pois a conscientização, por meio da educação, é indispensável ao aprimoramento do atual contexto social e político. A busca do ser humano pela liberdade e o encorajamento de suas ações oportunizam a evolução do sujeito no mundo
\end{abstract} Palavras-chave: Educação; Enfermagem; Filosofia; Liberdade; Vulnerabilidade em saúde.

\begin{abstract}
Objective: reflect on the concept of health vulnerability in light of Hannah Arendt's assumptions on education and freedom Method: a theoretical-reflexive study whose results were grouped into two categories:Vulnerability in health as a human condition and Education and freedom of the subject in a vulnerable situation. Results: vulnerability must be recognized as a feature of the human condition, because its dimensions involve the subject and their health, material, socio-environmental, cultural and legal conditions. When considering vulnerability from a political and awareness-raising perspective, education emerges as a tool to overcome it, for it makes it possible to develop the singularities of the subjects, preparing them for their responsibility to the world; it enables them to overcome alienation; it materializes political learning and decision making. All of this together is crucial to overcome the condition of vulnerability to the inequalities existing in the world and the respect for the subjects' freedom Conclusion and implications for practice: arendtian thoughts are related to vulnerability, since awareness, through education, is indispensable to the improvement of the current social and political context. The human being's search for freedom and the encouragement of their actions enable the evolution of the subject in the world.
\end{abstract}

Keywords: Education; Nursing; Freedom; Philosophy; Health Vulnerability

\section{REsumen}

Objetivo: reflexionar sobre el concepto de vulnerabilidad en salud a la luz de los supuestos de educación y libertad de Hannah Arendt. Método: estudio teórico-reflexivo cuyos resultados se agruparon en dos categorías:Vulnerabilidad en salud como condición humana y Educación y libertad del sujeto en situación de vulnerabilidad. Resultados: la vulnerabilidad debe ser reconocida como un rasgo de la condición humana, ya que sus dimensiones involucran al sujeto y sus condiciones de salud, materiales, socioambientales, culturales y legales. Al considerar la vulnerabilidad desde una perspectiva política y de sensibilización, la educación surge como una herramienta para superarlas, ya que permite desarrollar las singularidades de los sujetos, preparándolos para la responsabilidad con el mundo; permite superar la alienación; materializa el aprendizaje político y la toma de decisiones. Todo esto en conjunto es fundamental para superar la condición de vulnerabilidad ante las desigualdades existentes en el mundo y el respeto a la libertad de los sujetos. Conclusión e implicaciones para la práctica: los pensamientos arendtianos están relacionados con la vulnerabilidad, ya que la conciencia, a través de la educación, es fundamental para mejorar el contexto social y político actual. La búsqueda por la libertad de los seres humanos y el estímulo de sus acciones brindan oportunidades para la evolución del sujeto en el mundo.

Palabras clave: Educación; Enfermería; Filosofía; Libertad; Vulnerabilidad en Salud.
Autor correspondente:

Virna Ribeiro Feitosa Cestari.

E-mail: virna.ribeiro@hotmail.com

Recebido em 08/06/2021.

Aprovado em 12/08/2021.

DOI:https://doi.org/10.1590/2177-9465-EAN-2021-0207 


\section{INTRODUÇÃO}

O mundo encontra-se em estado de ruptura. Diariamente, pessoas são confrontadas com desigualdades e fragilização de direitos humanos e sociais ${ }^{1}$. Comumente, os mais prejudicados são também os inseridos em contextos de vulnerabilidade, o que limita sua reação e resistência. A preocupação com a vulnerabilidade encontrou, na saúde, campo fértil de ações integrais e intersetoriais fulcradas nos direitos humanos ${ }^{2}$. Resistir à condição de vulnerabilidade requer compreender cenários que a consolidam e avaliar estratégias para a sua superação por meio de mobilização que oportuniza uma sociedade liberta. A liberdade é política porque está atrelada à preocupação com o mundo. É um fenômeno aberto à experiência humana em circunstâncias nas quais os seres humanos estão em contato com prerrogativas essenciais a seu aparecimento ${ }^{3}$.

À medida em que vulnerabilidade e liberdade se entrelaçam, o conceito de educação aflora dessa relação, pois alicerça a compreensão de direitos, deveres e benefícios, contribuindo para o entendimento necessário a cobrar, das autoridades, um trabalho eficiente, promotor de bem-estar à sociedade 4 . Somente com acesso à educação, o homem pode interromper seu presente vulnerável e começar novo futuro, com ação livre no mundo ${ }^{3}$. Para tanto, é necessário empoderar e capacitar o sujeito para proteger-se e reagir às situações que o colocam em condição de vulnerabilidade.

Com o intuito de consolidar ações para a conscientização do sujeito, a Enfermagem incorpora, na sua prática educacional, o compromisso social e ético e o cuidado humanístico. Assim, quando ancorada na filosofia e em aportes sociais, políticos e culturais, permite a desconstrução seguida da reconstrução dos sujeitos, agora conscientes das suas ações no mundo. A filósofa e teórica política Hannah Arendt (1906 - 1975), ao estudar totalitarismo, direitos políticos e humanos; condição e espírito humano; educação e liberdade, debruçou-se sobre esses e outros conceitos para compreender a relação da humanidade plural com o mundo.

É oportuno ressaltar que educação e vulnerabilidade persistem articuladas nas questões referentes à saúde; surgem com diferentes representações entre a equipe multiprofissional e influenciam o modo como o cuidado de Enfermagem pode ser produzido no sentido de minimizar situações de vulnerabilidade e atender às necessidades de saúde dos sujeitos relativas a melhores condições de saúde e qualidade de vida.

Neste estudo, o objetivo foi refletir sobre o conceito de vulnerabilidade em saúde à luz dos pressupostos emancipatórios de educação e liberdade de Hannah Arendt.

\section{REFERENCIAL TEÓRICO}

Hannah Arendt, judaica de origem germano-americana, nasceu em Hannover, Alemanha, e foi aluna de Martin Heidegger, Karl Jaspers e Edmund Husserl. Para fugir do nazismo, exilou-se nos Estados Unidos, onde permaneceu até o fim de sua vida ${ }^{5}$. Sua obra é profundamente influenciada por suas experiências, sendo as principais: As Origens do Totalitarismo (1951); Entre o passo e o futuro (1957); A condição humana (1958) e O que é liberdade? (1961) ${ }^{6}$.

Diversos conceitos foram trabalhados por Arendt, contudo, o mundo comum e a condição humana aparecem como ponto inicial em seus discursos. A condição humana representa características da existência do homem em determinado espaço e é retratada pela vita activa, constituída por três atividades humanas fundamentais: labor, obra e ação, essenciais à vida ${ }^{7}$. A condição humana, que caracteriza o sujeito como ser social, torna improvável erradicar a vulnerabilidade. O sujeito deve reconhecer sua abrangência e tornar-se capaz de a ela responder.

Já o mundo comum é conjunto de heranças simbólicas e materiais, produto das obras humanas. Por ser comum, interpõe-se entre os homens, permitindo sua união e também sua separação, significando suas ações, histórias e memórias ${ }^{8}$. É neste mundo que as situações de vulnerabilidade emergem, oriundas de características inerentes ao indivíduo em suas precariedades, aliadas às desigualdades e fragilidades sociais. Os sujeitos não nascem iguais, são singulares. O mundo revela-se à pluralidade humana, em uma realidade compartilhada, confirmando a condição humana plural $^{9}$. É na convivência comunitária que o sujeito expõe sua singularidade em meio à pluralidade.

Arendt apresentou a pluralidade humana como fato sem escolha, constitutivo do humano na Terra. Assim, a partir do momento em que o homem está no mundo, as questões mundanas lhe pertencem ${ }^{8}$. Quando o homem opta por pertencer ao mundo, assume o amor mundi, espaço da vulnerabilidade, e torna-se responsável por seus atos e pela consequência de suas escolhas. Disso, emergem educação e responsabilidade, que, atreladas aos conceitos anteriores, potencializam a liberdade e o pensamento.

Dentre os filósofos da Fenomenologia, Arendt discursou sobre educação para compreender eventos e a crise do mundo moderno. A educação é o meio pelo qual o homem adquire experiência para escolher como pensar e que verdade defender ${ }^{10}$. As atividades de pensamento e compreensão empreendidas por Arendt, em sua reflexão sobre conceito e significado da educação, não configuram proposta prática ao professor ou à escola. Ela propôs a compreensão como chave para o homem aprender a lidar com o que o cerca e sentir-se em casa no mundo. Ela convidou a pensar sobre o sentido da educação e o consequente julgamento de princípios e objetivos ${ }^{11,12}$.

Os pressupostos de Hannah Arendt contribuem para exercer a igualdade e tecer a sociabilidade ante a pluralidade e visibilidade dos homens em situações de vulnerabilidade, levando-os da liberdade à tomada de decisões, aprendendo sobre a vida no coletivo e favorecendo múltiplas vivências sociais. Por isso, tais pressupostos reverberam na práxis da Enfermagem ao reforçar o enfrentamento da desigualdade e incentivar a adoção de iniciativas propulsoras de saúde.

\section{MÉTODO}

Estudo teórico-reflexivo fundamentado nos pressupostos de Hannah Arendt. Inicialmente, foi realizada busca de livros, 
artigos científicos e documentos em bases de dados da saúde, nacionais e internacionais, que abordassem os conceitos estudados pela filósofa. A busca dos artigos científicos deuse na Biblioteca Virtual em Saúde (BVS), Scientific Electronic Library Online (SciELO), Cumulative Index to Nursing and Allied Health Literature (CINAHL) e portal PubMed, em março de 2021. Foram utilizados como descritores: educação, liberdade e vulnerabilidade em saúde. Acrescentaram-se, à equação, a palavra-chave vulnerabilidade e o nome de Hannah Arendt para melhor direcionamento dos resultados.

Localizados os artigos, seguiu-se com o aprofundamento teórico. A construção dos eixos da reflexão foi ancorada teoricamente no conceito de vulnerabilidade e nos pressupostos arendtianos educação e liberdade. Os resultados foram agrupados em duas categorias: Vulnerabilidade em saúde como condição humana; Educação e liberdade do sujeito em situação de vulnerabilidade.

\section{RESULTADOS E DISCUSSÃO}

\section{Vulnerabilidade em saúde como condição humana}

O termo Vulnerabilidade em Saúde (VS) é relativamente novo e ganhou destaque no século XXI. Os percursores do movimento de construção desse conceito foram os pesquisadores americanos Mann, Tarantola e Netter, suscitado com o surgimento da Aids nos anos 1980. O enfoque da VS chamou a atenção para a necessidade de se atuar sobre determinantes políticos econômicos, sociais e culturais envolvidos no HIV/Aids, melhor entendidos sob os princípios universais de Direitos Humanos ${ }^{13}$.

No contexto epidemiológico, a construção conceitual da vulnerabilidade configura a superação do preconceito inspirado pela identificação de grupos de risco e da culpabilização individual que acompanhavam a focalização nos comportamentos de risco ${ }^{14}$. Ao partir da inseparabilidade da teoria e da prática, Ayres ${ }^{14}$ ressaltou o caráter hermenêutico da vulnerabilidade em saúde e direitos humanos. Para o autor, estudar uma questão de saúde na perspectiva da vulnerabilidade é buscar um modo de compreender melhor ou de outros modos um problema de saúde. É superar a fatoração dos determinantes contextuais na explicação da vulnerabilidade, trabalhando-se com diversos aspectos, sejam eles individuais, sociais ou programáticos, todos implicados no adoecimento ${ }^{13}$.

A vulnerabilidade perpassa o direito e a saúde: gera posturas que disseminam ideias de inserção social dos fragilizados, do indivíduo ao coletivo. Abrange finitude, susceptibilidade, incapacidades, autonomia e consciência; o pensamento científico social e político, com a culpabilização de indivíduos e populações em situações de fragilidade explícita. Recorre ao espaço ambiental e seus circuitos de produção econômica e social; vincula-se à garantia da cidadania de populações politicamente fragilizadas na perspectiva de direitos humanos e focalização de comportamentos de risco ${ }^{15}$.

Atualmente, duas novas definições de vulnerabilidade foram desenvolvidas por enfermeiras e publicadas em periódicos nacionais. A primeira definição baseia-se na abordagem fenomenológica e traz VS como fenômeno multidimensional, contextual e dinâmico, intrínseco à existência humana, resultante da interação entre pessoa humana, copresenças e cuidado, que acarreta agravos à saúde ou possibilita a evolução do indivíduo ou coletividade ${ }^{16,17}$.

A segunda definição veio em um modelo conceitual no qual VS foi definida como a condição de vida humana expressa em todas as suas dimensões a partir dos (re)arranjos das relações de poder, que constituem o sujeito-social, produzindo precariedade quando os movimentos de agenciamento não são potencializados para a promoção da saúde. ${ }^{13} \mathrm{~A}$ evolução das definições da VS tem possibilitado a expansão do termo e agregado elementos essenciais, que aclaram o seu conceito.

$\mathrm{Na}$ busca pela compreensão dos diversos processos de saúde-doença, Ayres et al. ${ }^{18}$ trouxeram aspectos a serem considerados nas três dimensões da análise de VS, com enfoque na hermenêutica. Ao apreender a VS na perspectiva do sujeito-social, Florêncio e Moreira ${ }^{13}$ elencaram subconceitos, alicerçados no pós-estruturalismo, e extraíram significados do conceito, organizando-os em três grandes grupos: risco (exposição, fator de risco, probabilidade, possibilidade, potencial e chance), suscetibilidade (fragilidade, ferida, estado de ameaça, experiência e posicionalidade) e precariedade (privação, desproteção, capacidade reduzida e precariedade). Esses significados demonstram a dinamicidade e o amadurecimento do conceito, que ganha espaço como mediador e produtor da práxis no campo da saúde.

Como exposto, foi possível observar a evolução e expansão do conceito e, pelos achados, perceber que a VS é vivenciada na invisibilidade pública, que aponta um sujeito revelado na experiência da dessubjetivação ${ }^{1}$. Assim, o conceito ganha cunho relacional sob a perspectiva de condição humana, característica essencial do sujeito-social, e estreita laços com ideias aredntianas.

Em seus estudos, Arendt discorreu sobre as características da existência do ser em determinado espaço. Para a filósofa, a condição humana diz respeito às formas de vida que o ser impõe a si mesmo para suprir suas necessidades e sobreviver. Portanto, varia com o lugar e o momento histórico vivido pelo homem. ${ }^{3} \mathrm{O}$ ser é caracterizado por porosidade estimulada pelo engajamento em seus próprios atos, pensamentos e sentimentos, pelo meio natural e as relações humanas ${ }^{19,20}$. Nesta seara, a compreensão existencial do ser condicionado e condicionante encontra-se vinculada à concepção da multideterminação da vulnerabilidade.

A vulnerabilidade deve ser reconhecida como traço da condição humana, na sua irredutível finitude e fragilidade. ${ }^{16}$ Refletir sobre as dimensões da vulnerabilidade que envolvem o indivíduo e a coletividade é ponderar sobre as condições materiais, socioambientais, culturais, jurídicas e subjetivas. Tal perspectiva remete à questão da mudança que as pessoas podem passar. ${ }^{13}$ Assim, as atividades e capacidades humanas, como trabalhar, criar, conhecer, pensar, educar, são decisivas para transpor o conformismo, a habitualidade e a previsibilidade. Além disso, abundam estudos sobre o conceito de vulnerabilidade, mas 
poucos contribuem para uma ontologia que enlace ser social, intermediado pela educação, autonomia e cuidado.

Há a necessidade de ponderar questões críticas relativas ao cuidado e às pesquisas com sujeitos que vivenciam situações de vulnerabilidade e sofrem graves iniquidades, com comprometimento da saúde. É promissor, portanto, resgatar a educação para a potencialização do protagonismo do sujeito em vulnerabilidade e como ferramenta de ação dos enfermeiros. Para fazer isso, propõe-se a exploração de ideias arendtianas sobre educação e liberdade, articulando-as às ações da Enfermagem.

\section{Educação e liberdade do sujeito em vulnerabilidade}

Muitos educadores foram fundamentais à atual compreensão de educação como novo paradigma, em busca da conquista de um país mais justo, solidário e democrático. Paulo Freire, Dermeval Saviani, Célestin Freinet, Rudolf Steiner, Maria Montessori e Rubem Alves são personagens indispensáveis na história da educação brasileira, por abordarem liberdade e empoderamento ${ }^{21}$ na educação básica e superior ${ }^{22}$, construindo uma pedagogia inclusiva ${ }^{23}$ e cooperativa ${ }^{24}$, com garantia de direitos ${ }^{25}$ e valorização da individualidade de educando-educador ${ }^{26}$

Nessa expectativa, por uma educação politizada e da necessidade de sua remodelação para suprir as demandas sociais, as obras de Hannah Arendt têm despertado atenção de educadores pela originalidade, força e independência pensante de que há fé na natalidade com a revelação de um novo alguém no mundo, um ser singular capaz de começar algo inédito e imprevisto e de renovar o mundo comum ${ }^{12}$. Mas, como o pensamento de Hannah Arendt influencia ações pedagógicas para o sujeito reconhecer e transpor situações de vulnerabilidade? Tal questão orientou a busca por reflexões que expressem o potencial da educação em ações para a transformação do mundo e a diminuição da condição de vulnerabilidade.

Vulnerabilidade não é um conceito trabalhado por Arendt, embora seja imprescindível pensá-la sob uma perspectiva política e conscientizadora. Para tanto, é preciso desvincular a interpretação da VS sob o ponto de vista exclusivamente individual, que culpabiliza o sujeito pela sua situação, e expandi-la à condição humana. Ao considerar que o caráter político e social constitui o cerne das atividades humanas e implica, diretamente, a produção do mundo, a educação desvela-se como meio para a conscientização e a prática da liberdade dos sujeitos.

Arendt não estabeleceu relação direta entre educação $e$ liberdade, mas ambos os conceitos se sustentam na natalidade ${ }^{27}$. Cada nascimento é um começo, com oportunidades de mudanças, em que educadores contribuem para o desenvolvimento da singularidade, norteados pela dimensão do público ${ }^{12}$. A educação é o espaço e o tempo em que o homem se prepara para mudar o mundo; é o ponto em que decide amar o mundo e assumir sua responsabilidade sobre ele ${ }^{10}$. Por conseguinte, é lógico pensar a educação como ferramenta para a identificação e a superação da VS.
Reinterpretar os pressupostos de Arendt no contexto dos cuidados de saúde é transpor a imposição de procedimentos técnicos e assumir que o cuidado dos profissionais pode ser visto como modos de ação. Assim, a suplantação das condições de VS pode advir do sujeito que tem sua compreensão de mundo ampliada pela educação e pela mediação de profissionais, como o enfermeiro, pois estes têm, na sua formação, a educação em saúde como instrumento para a proteção e promoção da saúde, atuando, assim, nessa corresponsabilização pela natalidade do sujeito.

Devido aos fatores que caracterizam a VS, a ação humana, implicada no coletivo, envolve aspectos ético-políticos focados na pluralidade dos sujeitos e espaços públicos. É nesse cuidar do comum que a educação emerge como ato e estreita seu vínculo com a vulnerabilidade, pois convida o sujeito a repensar suas práticas. Ayres ${ }^{14}$ propôs a ação associada ao contexto histórico e social, pelo trabalho com diferentes setores da sociedade e da transdisciplinaridade, o que contribui, de maneira crítica e dinâmica, para mudanças políticas, culturais, cognitivas e tecnológicas.

A educação permite que o sujeito entenda desafios e tensões nas esferas físicas, emocionais, sociais, econômicas e políticas; influencia o planejamento e a implementação de ações preventivas, protetivas e proativas, viabilizando a construção de contextos saudáveis ${ }^{28}$. É necessário destacar que o reconhecimento para sobrepujar situações de vulnerabilidade depende da compreensão dos sujeitos acerca de si, das relações, dos contextos e dos seus direitos e deveres. Essa captação da realidade dá-se pela conscientização com a reorganização das ações e reflexões.

É equivocado pensar que o homem chega ao mundo livre das influências mundanas. O nascimento é condicionado pela condição do sujeito no mundo, e quando, conscientemente, opta por agir, o homem renasce, ou seja, assume a responsabilidade pelo mundo e seus desdobramentos (Figura 1). Contudo, para que isso aconteça, é necessário que os educadores apresentem o mundo ao aprendiz, ensinem seus saberes e suas ciências e estimulem a partilha dos conhecimentos do mundo para que novos fundamentos sejam agregados e os defasados sejam substituídos. Esta construção compartilhada implica um processo comunicacional e pedagógico entre sujeitos de saberes diferentes convivendo em situações de interação e cooperação ${ }^{15}$.

Nesse transcurso, a educação deve garantir proteção do homem para que ele desenvolva sua singularidade pensando na pluralidade, porque só assim é viável estabelecer espaço compartilhado. Isso é possível quando o homem é educado nas dimensões política (atualizada na ação), ontológica (natalidade é fonte das atividades humanas livres) e a interior ou mental (característica fundamental das atividades do pensar e do querer) ${ }^{3,10}$. Esses conhecimentos implicam a autonomia do sujeito, agora politizado e ciente de seus direitos.

Ao tomar a política como modos coletivos de decidir sobre a maneira como se quer viver e conduzir os assuntos públicos, o sujeito defende o compromisso com vidas oprimidas e a participação nos processos de decisão. ${ }^{8} \mathrm{~A}$ construção do 


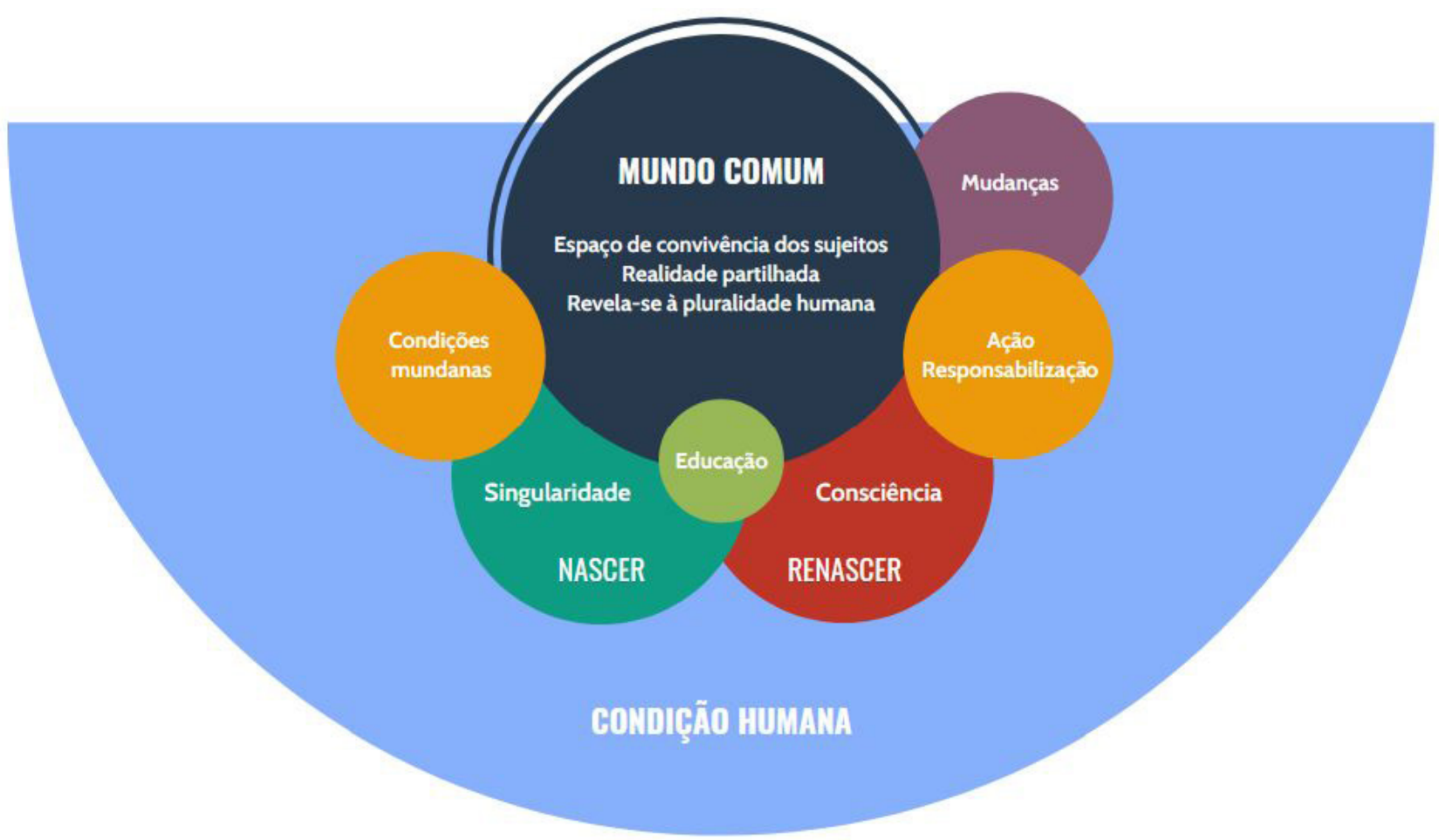

Figura 1. Relação entre condição humana e mundo comum na perspectiva arendtiana. Fortaleza, CE, Brasil, 2021.

sujeito como ser político deve ser provida pelo Estado, também responsável pelo investimento naquilo que constrói e constitui cidadania, naqueles atributos que transformam o indivíduo em cidadão. Essa transformação, pressuposto da democracia, permite, ao sujeito, ir do reino da necessidade para o da liberdade ${ }^{10}$.

Em contrapartida, ressalta-se a influência das doutrinas econômicas vigentes no modelo educacional brasileiro. O ideário neoliberal, disseminado desde o século passado, encontra, na política de austeridade, a possibilidade de enfraquecimento das políticas sociais de caráter universal, com graves efeitos sociais: subgrupos populacionais mais vulneráveis socialmente são mais negativamente afetados, em todos os contextos ${ }^{29}$. Esse retrocesso representa o fracasso do juízo humano e marca a crise da educação. Todavia, lograr o nascimento à educação é expandir o potencial de crescimento da sociedade e estimular o senso comum para a proteção do daqueles em condição de vulnerabilidade.

Para intervir em situações de vulnerabilidade, é imperativo estimular e ensinar o desenvolvimento de ações que envolvam resposta social, marcada pela participação ativa da população na procura de estratégias passíveis de execução e encaminhamento/ equacionamento de problemas e necessidades dos sujeitos ${ }^{14,18}$. A educação opera sobre a singularidade do homem a fim de prepará-lo para fazer algo inteiramente novo.

No pensamento arendtiano, a liberdade é entendida como fato demonstrável, cuja manifestação está sujeita à existência de domínio público, politicamente assegurado como espaço concreto onde é possível que as pessoas realizem seus atos e profiram suas palavras umas às outras ${ }^{30}$. Palavra e ação não se separam, precisam estabelecer uma instância de poder cujo fundamento está na relação e possibilidade de criar novas realidades ${ }^{3,10}$. A liberdade não é atributo da vontade, mas a expressão da ação manifesta pela palavra.

É na compreensão do sujeito como ser no mundo que ele se reconhece como autêntico, livre para transcender sobre o mundo e si mesmo, saindo da indiferença da vida cotidiana ${ }^{16}$. Mediada pela educação, a relação humana com o mundo encontra a liberdade na vita activa e suas atividades. O labor é considerado atividade que conduz o homem do nascimento à morte; é processo biológico corpóreo humano. A obra consiste na não naturalidade da existência humana e produz o mundo artificial de objetos, das coisas duráveis, onde o homem cria o próprio mundo. A ação é a que se exerce diretamente entre os homens; corresponde à condição humana da pluralidade e dá-se em uma esfera puramente intersubjetiva ${ }^{3}$.

Aqui, apreende-se a educação como ação para a liberdade, que liberta o homem da sua incapacidade de não refletir e criar. Assim, ação e liberdade entrelaçam-se, pois é a ação que torna possível o exercício da liberdade: enquanto a liberdade traz, em seu bojo, a possibilidade de iniciar ou mesmo de reiniciar, ultrapassando a condição de VS, é pela ação que se exprime seu domínio de experiências.

Apoiada nos referenciais de vulnerabilidade e pressupostos arendtianos, a Enfermagem pode concentrar suas ações educativas na compreensão da interlocução do sujeito com o coletivo e, assim, fomentar a construção de saberes: em atividades grupais 
que estimulem a fala e a criação de ambientes saudáveis e sustentáveis por meio do conhecimento compartilhado; na identificação e avaliação das necessidades que extrapolam o processo de saúde-doença e ao considerar a singularidade, as diversidades das vivências e os processos identitários na edificação de um mundo melhor para as futuras gerações.

Essas ações revelam-se pujantes para o empoderamento de sujeitos em condição de vulnerabilidade e ecoam na saúde quando fundamentadas na empatia, colaboração e solidariedade; possibilitam mudanças sociais, corroborando o fortalecimento e a elaboração de políticas públicas e conferem, aos sujeitos, meios para assegurar maior controle e melhoria de sua própria saúde, contribuindo com ações de responsabilidade.

Atualmente, a educação é marcada pelo acúmulo de saberes e habilidades em detrimento da criatividade e da capacidade de reflexão. No intuito de apoiar a didática e, pedagogicamente, uma proposta de formação, Arendt trabalhou com a criação de biografias imaginárias e narrativas, despertando a potencialidade da escrita criativa para aprimorar as capacidades do sujeito. Dessa forma, estimulava possibilidades de ação: para o sujeito pensar e situar-se no contexto vivido ${ }^{11}$. Trabalhar o reconhecimento de si e do meio em que vive é concretizar o aprendizado político, o pertencimento e tomar decisões a respeito das questões relacionadas ao mundo comum. Essa consciência é crucial para suplantar a VS em tempos de grande instabilidade e desigualdades.

Os pressupostos arendtianos orientam a reflexão sobre o sujeito e seus contextos de saúde, políticos, civis, sociais, culturais, econômicos e ambientais; essa consciência fundamenta o respeito à integridade do homem como ser singular, em sua própria história, e plural ao conviver com os outros. Ao discursar sobre o totalitarismo, Arendt descreveu a vida nua e a desproteção daqueles que ladeiam a sociedade, e foi na educação que a filósofa refutou a alienação dos sujeitos e, assim, deu voz àqueles em estado de vulnerabilidade, oportunizando transformações.

O cuidar da Enfermagem, com enfoque na educação e vulnerabilidade, estimula o sujeito a compreender e a desenvolver um olhar crítico e dialético na sua relação com o mundo, não importando o quão imerso na cultura do silêncio esteja. Conquistar e socializar saberes que alarguem os conhecimentos, com enfoque na responsabilização, no cuidado com o mundo e o outro, são imprescindíveis à perpetuação da vida humana ${ }^{8}$. O homem deve ser estimulado a pensar e a conhecer. Pensar a vulnerabilidade, educação e liberdade sob a ótica de uma prática cidadã e de direito, conforme preconizou Arendt, poderia levar a acreditar que o homem nasceu para começar ${ }^{19}$.

As reflexões produzidas levaram à concepção de que, por meio da educação, o homem em situação de vulnerabilidade reconhece-se cidadão; desperta e compreende seus direitos e deveres, aceita sua responsabilidade como sujeito de ação e relação e luta por sua liberdade e uma sociedade liberta via atividades construtivas e constitutivas para o mundo. Esse despertar pode e deve ser fortalecido pelo enfermeiro, como difusor de conhecimentos e educador de uma nova geração, estimulando os sujeitos a assumirem-se como seres conscientes, com capacidade de dialogar e atentos à saúde individual, coletiva e respeitosa para o outro e com o meio em que vive.

\section{CONCLUSÃO E IMPLICAÇÕES PARA A PRÁTICA}

Ficou evidente que a filosofia e os pensamentos arendtianos guardam relação com a vulnerabilidade. A Enfermagem assume papel importante na educação e conscientização dos sujeitos, indispensáveis no contexto social e político e na busca pela liberdade. A educação desvela-se como estratégia inclusiva essencial na luta contra as iniquidades e, por meio desta, a pluralidade é vivenciada, compreendida e transformada, no movimento para o reconhecimento das situações de vulnerabilidade e capacitação para a superação, sem ignorar a condição humana. Embasar as ações educativas da Enfermagem em Hannah Arendt é oportunizar a construção de um mundo mais justo, favorecendo a evolução do homem enquanto ser singular e plural.

Como limitações do estudo, destaca-se que poucas pesquisas sobre educação na Enfermagem brasileira fundamentam-se nas ideias arendtianas. Com isso, são necessários estudos futuros, que abordem a educação sob a perspectiva da filósofa, por elevarem o sujeito à condição de autor principal de vida, consciente do contexto social.

\section{CONTRIBUIÇÕES DOS AUTORES}

Desenho do estudo de reflexão. Virna Ribeiro Feitosa Cestari. Vera Lúcia Mendes de Paula Pessoa. Thereza Maria Magalhães Moreira.

Levantamento do referencial teórico. Virna Ribeiro Feitosa Cestari. Raquel Sampaio Florêncio.

Análise do referencial teórico. Virna Ribeiro Feitosa Cestari. Raquel Sampaio Florência. Vera Lúcia Mendes de Paula Pessoa. Thereza Maria Magalhães Moreira.

Interpretação. Virna Ribeiro Feitosa Cestari. Vera Lúcia Mendes de Paula Pessoa. Thereza Maria Magalhães Moreira.

Redação e revisão crítica do manuscrito. Virna Ribeiro Feitosa Cestari Raquel Sampaio Florêncio. Vera Lúcia Mendes de Paula Pessoa. Thereza Maria Magalhães Moreira.

Aprovação da versão final do artigo. Virna Ribeiro Feitosa Cestari. Raquel Sampaio Florêncio. Vera Lúcia Mendes de Paula Pessoa. Thereza Maria Magalhães Moreira.

Responsabilidade por todos os aspectos do conteúdo e a integridade do artigo publicado. Virna Ribeiro Feitosa Cestari. Raquel Sampaio Florêncio. Vera Lúcia Mendes de Paula Pessoa. Thereza Maria Magalhães Moreira.

\section{EDITOR ASSOCIADO}

Marta Sauthier (D)

\section{EDITOR CIENTÍFICO}

Ivone Evangelista Cabral (D) 


\section{REFERÊNCIAS}

1. Anbeek C. The courage to be vulnerable: philosophical considerations. Int J Philosophy Theology. 2021;82(1):64-76. http://dx.doi.org/10.1080 /21692327.2021.1880962.

2. Enang I, Murray J, Dougall N, Wooff A, Heyman I, Aston E. Defining and assessing vulnerability within law enforcement and public health organisations: a scoping review. Health Justice. 2019;7(1):2. http:// dx.doi.org/10.1186/s40352-019-0083-z. PMid:30825016.

3. Arendt H. A condição humana. 13 $3^{\underline{a}}$ ed. Rio de Janeiro: Forense Universitária; 2016.

4. Winter AC, Menegotto LMO, Zucchetti DT.Vulnerabilidade social e educação: uma reflexão na perspectiva da importância da intersetorialidade. Conh Diversidade.2019;11(25):165-83. http://dx.doi.org/10.18316/rcd.v11i25.5526.

5. Garret PM. Hannah Arendt and social work: a critical commentary. Qual Soc Work. 2019;1-18. http://dx.doi.org/10.1177/1473325019887778.

6. Shymko Y, Frémeaux S. Escaping the fantasy land of freedom in organizations: the contribuition of Hannah Arendt. J Bus Ehtics. 2021. http://dx.doi.org/10.1007/s10551-020-04707-x.

7. Sousa YG, Medeiros SM, Santos VEP, Temoteo RCA, Carvalho JBL. The human condition og the nursing worker from the perspective of Hannah Arendt. Rev Bras Enferm. 2020;73(1):e20170727. http://dx.doi. org/10.1590/0034-7167-2017-0727. PMid:32049213.

8. Martinez CT, Machado AM. Diálogos entre o método da cartografia e alguns pressupostos filosóficos de Hannah Arendt na pesquisa em educação. Interface (Botucatu). 2021;25:e190835. http://dx.doi. org/10.1590/interface.190835.

9. Cenci AV, Casagranda EA. Alteridade, acão e educação em Hannah Arendt. Cad Pesq. 2018;48(167):172-91. http://dx.doi.org/10.1590/198053144664.

10. Arendt H. Entre o passado e o futuro. 8 ed. São Paulo: Perspectiva;2016.

11. Palma D, Sá APS, Barros NN, Sachs RS. Storytelling and the pleasure of getting used to: exercises in imagination for writing practice in human rights education. Trab Ling Aplic. 2018;57(2):699-730. http://dx.doi.org /10.1590/010318138651914365851.

12. Briskievicz DA. A ontologia da singularidade e a educação em Hannah Arendt: uma preparação para o mundo. Rev Port Educ. 2018;31(1):7983. http://dx.doi.org/10.21814/rpe.12082.

13. Florêncio RS, Moreira TMM. Modelo de vulnerabilidade em saúde: esclarecimento conceitual na perspectiva do sujeito-social. Acta Paul Enferm. 2021;34:eAPE00353. http://dx.doi.org/10.37689/actaape/2021AO00353.

14. Ayres JRCM. Vulnerabilidade, direitos humanos e cuidado: aportes conceituais. In: Barros S, Campos PFS, Fernandes JJS, organizadores. Atenção à saúde de populações vulneráveis. Barueri, SP: Manole;2014

15. Sevalho $\mathrm{G}$. The concept of vulnerability and health education based on the teory laid out by Paulo Freire. Interface. 2018;22(64):177-88. http:// dx.doi.org/10.1590/1807-57622016.0822.

16. Cestari VRF, Moreira TMM, Pessoa VLMP, Florêncio RS, Silva MRF Torres RAM. The essence of care in health vulnerability: a Heideggerian construction. Rev Bras Enferm. 2017;70(5):1112-6. http://dx.doi. org/10.1590/0034-7167-2016-0570. PMid:28977242.

17. Cestari VRF, Moreira TMM, Pessoa VLMP, Florêncio RS. Insuficiência cardíaca: interface com a vulnerabilidade em saúde. Curitiba: Ed CRV 2019. http://dx.doi.org/10.24824/978854443499.4.

18. Ayres JRCM, Calazans GJ, Saletti HC Fo, França I Jr. Risco, vulnerabilidade e práticas de prevenção e promoção da saúde. In: Campos GWS Bonfim JRA, Minayo MCS, Akerman M, Drumond M Jr, Carvalho YM, organizadores. Tratado de saúde coletiva. $2^{\mathrm{a}}$ ed. São Paulo: HUCITEC Editora; 2012

19. Aguiar OA. Hannah Arendt e o direito (parte II): outlaw e o direito a ter direitos. Kriterion.2019;143(143):403-15. http://dx.doi.org/10.1590/0100512x2019n14309oaa.

20. Wuensch AM, Cabrera J. Bioética e condição humana: contribuições para pensar o nascimento. Rev Bioet. 2018;26(4):484-93. http://dx.doi. org/10.1590/1983-80422018264266

21. Heideman ITSB, Souza JB, Santos DG, Oliveira DR, Marques LC Empoderamento: reflexões no contexto das vulnerabilidades e das práticas de enfermagem. Rev Baiana Enferm. 2021;35:e36399. https:// doi.org/10.18471/rbe.v35.36399.

22. Gama CN, Duarte N. Concepção de currículo em Dermeval Savian e suas relações com a categoria marxista de liberdade. Interface (Botucatu). 2017;21(62):521-30. http://dx.doi.org/10.1590/180757622016.0922.

23. Elias MDC. Celestin Freinet: uma pedagogia de atividade e cooperação 9a ed. Petrópolis: Editora Vozes; 2010.112 p.

24. Alves R. A escola com que sempre sonhei sem imaginar que pudesse existir. 12a ed. Campinas: Papirus Editora; 2010.

25. Romano A. Maria Montessori: a complex and multifaceted historiographica subject. Hist Psychol. 2020;23(2):203-7. http://dx.doi.org/10.1037/ hop0000150. PMid:32378916.

26. Wagemann J, Edelhäuser F, Weger U. Outer and inner dimensions of brain and consciousness: refining and integrating the phenomenal layers. Adv Cogn Psychol. 2018;14(4):167-85. http://dx.doi.org/10.5709/ acp-0248-2.

27. Almeida VS. Educação e liberdade em Hannah Arendt. Educ Pesqui 2008;34(3):465-79. http://dx.doi.org/10.1590/S1517-97022008000300004.

28. Macedo JKSS, Costa LPS, Lima AFS, Lima JLR, Vasconcelos BMV Santos AAP. Vulnerability and its dimensions: reflections on nursing care for humans groups. Rev Enferm UERJ. 2020;28:e39222. http:// dx.doi.org/10.12957/reuerj.2020.39222.

29. Santos IS, Vieira FS. The right to healthcare and fiscal austerity: the Brazilian case from an international perspective. Cien Saude Colet. 2018 jul;23(7):2303-14. http://dx.doi.org/10.1590/1413-81232018237.09192018. PMid:30020383.

30. Machado VA, Pinheiro R, Miguez SF. Educação e liberdade na promoção da saúde escolar: perspectivas compreensivas sobre a ação política como potência nas comunidades escolares. Interface (Botucatu). 2021;25:e200035. http://dx.doi.org/10.1590/interface.200035. 